Check for updates

Cite this: RSC Adv., 2019, 9, 31563

Received 10th September 2019 Accepted 18th September 2019

DOI: $10.1039 / c 9 r a 07258 f$

rsc.li/rsc-advances

\section{Nickel foam and stainless steel mesh as electrocatalysts for hydrogen evolution reaction, oxygen evolution reaction and overall water splitting in alkaline media $\dagger$}

\begin{abstract}
Xiaoyan Hu, ${ }^{a}$ Xuemei Tian, ${ }^{a}$ Ying-Wu Lin (D ${ }^{b}$ and Zhonghua Wang iD *a
In this work, several commonly used conductive substrates as electrocatalysts for hydrogen evolution reaction (HER) and oxygen evolution reaction (OER) under alkaline conditions were studied, including nickel foam (Ni foam), copper foam (Cu foam), nickel mesh (Ni mesh) and stainless steel mesh (SS mesh). $\mathrm{Ni}$ foam and SS mesh are demonstrated as high-performance and stable electrocatalysts for HER and OER, respectively. For HER, Ni foam exhibited an overpotential of $0.217 \mathrm{~V}$ at a current density of $10 \mathrm{~mA}$ $\mathrm{cm}^{-2}$ with a Tafel slope of $130 \mathrm{mV} \mathrm{dec}{ }^{-1}$, which were larger than that of the commercial Pt/C catalyst, but smaller than that of the other conductive substrates. Meanwhile, the SS mesh showed the best electrocatalytic performance for OER with an overpotential of $0.277 \mathrm{~V}$ at a current density of $10 \mathrm{~mA}$ $\mathrm{cm}^{-2}$ and a Tafel slope of $51 \mathrm{mV} \mathrm{dec}{ }^{-1}$. Its electrocatalytic performance not only exceeded those of the other conductive substrates but also the commercial $\mathrm{RuO}_{2}$ catalyst. Moreover, both $\mathrm{Ni}$ foam and SS mesh exhibited high stability during HER and OER, respectively. Furthermore, in the two-electrode system with $\mathrm{Ni}$ foam used as the cathode and SS mesh used as the anode, they enable a current density of $10 \mathrm{~mA} \mathrm{~cm}{ }^{-2}$ at a small cell voltage of $1.74 \mathrm{~V}$. This value is comparable to or exceeding the values of previously reported electrocatalysts for overall water splitting. In addition, $\mathrm{NiO}$ on the surface of $\mathrm{Ni}$ foam may be the real active species for $\mathrm{HER}, \mathrm{NiO}$ and $\mathrm{FeO}_{x}$ on the surface of SS mesh may be the active species for OER. The abundant and commercial availability, long-term stability and low-cost property of nickel foam and stainless steel mesh enable their large-scale practical application in water splitting.
\end{abstract}

\section{Introduction}

The increasing of energy demands and depleting of fossil fuels are vital challenging issues that call for the urgent discovering of alternative energy resources., ${ }^{\mathbf{1} 2}$ Hydrogen is considered as a promising alternative to traditional fossil fuels in the future due to its high energy density and environmental friendliness. ${ }^{3}$ Electrochemical water splitting, which consists of two halfreactions, namely oxygen evolution reaction (OER) and hydrogen evolution reaction (HER), is an appealing technology to obtain high-purity hydrogen. ${ }^{\mathbf{4} 5}$ The major challenge to accomplish the two half-reactions in electrochemical water splitting is to overcome the intrinsic sluggish kinetics of HER and OER, especially of OER that arise from a complex multistep

${ }^{a}$ Chemical Synthesis and Pollution Control Key Laboratory of Sichuan Province, College of Chemistry and Chemical Engineering, China West Normal University, Nanchong 637002, P. R. China.E-mail: zhwangs@163.com; zhwangs@cwnu.edu.cn; Fax: +86817 2445233; Tel: +868172568081

${ }^{b}$ School of Chemistry and Chemical Engineering, University of South China, Hengyang 421001, P. R. China

$\dagger$ Electronic supplementary information (ESI) available. See DOI: 10.1039/c9ra07258f proton-coupled electron transfer process. ${ }^{6,7}$ Currently, the stateof-the-art electrocatalysts for HER and OER are platinum (Pt) and ruthenium/iridium dioxide $\left(\mathrm{RuO}_{2} / \mathrm{IrO}_{2}\right)$ due to their low overpotential and Tafel slope. ${ }^{2, \mathbf{8}}$ However, these precious electrocatalysts suffer from scarcity and high-cost that limit their large-scale practical application to generate high-purity hydrogen resource economically by water splitting. Therefore, it is important to explore earth-abundant and low-cost alternatives. $^{2}$

In recent years, much effort has been made on the developing of inexpensive electrocatalysts for HER, OER and overall water splitting based on earth-abundant transition metals. For example, a large amount of transition metal oxides, ${ }^{\text {9-14 }}$ hydroxides, ${ }^{15-18}$ chalcogenides, ${ }^{19-22}$ phosphides, ${ }^{23-27}$ sulfides $^{28-32}$ and carbides ${ }^{33,34}$ have been explored as efficient and potential HER, ${ }^{19-30,32,34} \mathrm{OER}^{9-18,25-31,33}$ and overall water splitting electrocatalysts ${ }^{25,26,28-30}$ for the replacement of precious catalysts. To study the electrocatalytic activity of these catalysts, the first step is to load the catalyst on a conductive substrate either by directly grown or by coating via adhesives (such as Nafion). For instance, $\mathrm{Li}$ and co-workers prepared $3 \mathrm{D}$ urchin-like $\mathrm{Co}_{3} \mathrm{O}_{4}$ by directly 
grown on nickel foam and studied its OER, HER and overall water splitting performance. ${ }^{35}$ Telli and co-workers deposited iron and copper electrochemically on nickel mesh and studied its the catalytic performance of HER. ${ }^{36}$ Jiang and coworkers coated $\mathrm{Co}_{x} \mathrm{Mo}_{y} @ \mathrm{NC}$ on glassy carbon electrode (GCE) to study its HER, OER and the catalytic performance of overall water splitting. ${ }^{37}$ Chen and co-workers growned NiS on stainless steel mesh and studied the catalytic performance of OER. ${ }^{38}$ Fan and co-workers directly growned single nanocrystalline tungsten carbide (WC) on vertically aligned carbon nanotubes and studied its catalytic performance of HER ${ }^{39}$ Leem and co-workers deposited Ni(cyclam)-BTC on indium tin oxide (ITO) and studied the catalytic performance of OER. ${ }^{40}$ Yang and co-workers directly growned CoP nanosheet on carbon cloth and studied its catalytic performance of HER. ${ }^{41}$

However, the above mentioned studies only employed nickel foam, stainless steel mesh, etc. as conductive substrates, i.e. catalyst support, and the systematic study of the electrocatalytic performance for HER and OER of these commonly used conductive substrates has been rarely reported. ${ }^{\mathbf{4 , 4 2}}$ In this work, several commonly used conductive substrates, including nickel foam, copper foam, nickel mesh and stainless steel mesh were studied as electrocatalysts for hydrogen evolution reaction, oxygen evolution reaction under alkaline conditions. It was demonstrated that Ni foam and Ni mesh showed better HER activity and the SS mesh showed the best OER performance. The $\mathrm{Ni}$ foam requires relatively low overpotential of $0.217 \mathrm{~V}$ to produce a current density of $10 \mathrm{~mA} \mathrm{~cm}{ }^{-2}$, and the SS mesh shows a current density of $10 \mathrm{~mA} \mathrm{~cm}{ }^{-2}$ at a small overpotential of $0.277 \mathrm{~V}$ for the OER. At the same time, Ni foam and SS mesh showed long-term stability of the HER and OER, respectively. Furthermore, in the two-electrode system with the SS mesh used as anode and $\mathrm{Ni}$ foam used as cathode, they enable a current density of $10 \mathrm{~mA} \mathrm{~cm}^{-2}$ at a small cell voltage of $1.74 \mathrm{~V}$, which is comparable to or even better than some reported bifunctional water-splitting catalysts. Because Ni foam and SS mesh can be commercially available with low price that conferring their large-scale application in the production of hydrogen economically by electrochemical water splitting.

\section{Experimental section}

\subsection{Materials}

Potassium hydroxide (KOH) was purchased from Shanghai Titan Scientific Co., Ltd. Hydrochloric acid ( $\mathrm{HCl})$ and absolute ethanol were purchased from Chengdu Kelon Chemical Reagent Factory. Nafion solution (5 wt\%) purchased from Suzhou Yilong Energy Technology Co., Ltd. 20 wt\% platinum carbon $(\mathrm{Pt} / \mathrm{C})$ purchased from Kunshan Yierwei International Trade Co., Ltd. Ruthenium oxide $\left(\mathrm{RuO}_{2}\right)$ was purchased from Adamas. All chemicals were used as received without further purification. All electrolyte solutions were prepared with distilled water unless otherwise stated. Ni foam, SS mesh and $\mathrm{Cu}$ foam were obtained from Changde Liyuan New Materials Co., Ltd. ITO was purchased from Shenzhen Hua Nanxiang Technology Co., Ltd. Ni mesh was purchased from Anping
Kangwei Metal Wire Mesh Co., Ltd. Pt electrode, Ag/AgCl electrode and GCE were purchased from Wuhan Gaoshi Ruilian Technology Co., Ltd.

\subsection{Characterization}

The powder X-ray diffraction (XRD) measurements were recorded on a Rigaku Dmax/Ultima IV diffractometer with monochromatized $\mathrm{Cu} \mathrm{K} \alpha$ radiation $(\lambda=1.5418 \AA)$. The morphologies were observed by scanning electron microscopy (JSM-6530LV, Rigaku Japan). The surface composition and electronic structure were examined by X-ray photoelectron spectroscopy (XPS) on a ThermoFisher K-Alpha XPS spectrometer equipped with an Al K $\alpha$ X-ray source.

\subsection{Electrochemical measurements}

Electrochemical measurements were performed on an electrochemical workstation (CHI 760E, CH Instruments Inc, Shanghai) using a typical three-electrode setup with an electrolyte solution of $1 \mathrm{M} \mathrm{KOH}$, a Pt wire as the counter electrode, a $\mathrm{Ag} / \mathrm{AgCl}$ electrode as the reference electrode, and a conductive substrate with geometric area of $1 \mathrm{~cm}^{2}$ was employed as the working electrode. The working electrode was prepared as follows: firstly, the conductive substrate $\left(1 \mathrm{~cm}^{2}\right)$ (except ITO and GCE) was completely immersed in $3 \mathrm{M} \mathrm{HCl}$ for $15 \mathrm{~min}$ to well clean the surface, then washed with distilled water to insure the undefiled surface, and finally dried at room temperature. $5 \mathrm{mg}$ of $\mathrm{Pt} / \mathrm{C}\left(\right.$ or $\mathrm{RuO}_{2}$ ) and $10 \mu \mathrm{L}$ of Nafion were ultrasonically dispersed in $1 \mathrm{~mL}$ of mixture solution of water/alcohol (v/v $3: 1)$ for $30 \mathrm{~min} .5 \mu \mathrm{L}$ of the dispersion was deposited on GCE $(d=3$ $\mathrm{mm}$ ) and dried naturally.

All potentials measured were converted to the reversible hydrogen electrode (RHE) based on the following formula: $E_{\mathrm{RHE}}$ $=E_{\mathrm{Ag} / \mathrm{AgCl}}+0.197 \mathrm{~V}+0.059 \mathrm{pH}{ }^{43}$ Linear sweep voltammetry (LSV), cyclic voltammetry (CV), electrochemical impedance spectroscopy (EIS) and chronopotentiometry (CP) were carried out in $1 \mathrm{M} \mathrm{KOH}$ solution. Tafel slope was modeled by the empirical Tafel equation: $\eta=a+b \times \log |j|,{ }^{26}$ where $\eta$ is the overpotential, $j$ is the measured current density, $b$ is the Tafel slope, and $a$ is the constant. Electrochemical impedance spectroscopy (EIS) was measured with an amplitude of $5 \mathrm{mV}$. Without specification, all the potentials are referred to the RHE.

\section{Results and discussion}

\subsection{Characterization of materials}

The crystalline phases of these conductive substrate samples were analyzed by XRD. The Ni foam and Ni mesh have similar peaks that centered at about $44.5^{\circ}, 51.9^{\circ}$ and $76.4^{\circ}$ (Fig. 1, curves a and b), which can be indexed to the (111), (200) and (220) planes of nickel (PDF \#04-0850). The $\mathrm{Cu}$ foam shows three peaks at $43.3^{\circ}, 50.4^{\circ}$ and $74.1^{\circ}$ (Fig. 1, curve c), which are attributed to the (111), (200) and (220) planes of copper (PDF \#04-0836). The distinctive diffraction peaks at $43.6^{\circ}, 50.9^{\circ}$ and $74.7^{\circ}$ (Fig. 1, curve d) are corresponding to the (111), (200) and (220) planes of austenite (PDF \#33-0397). 


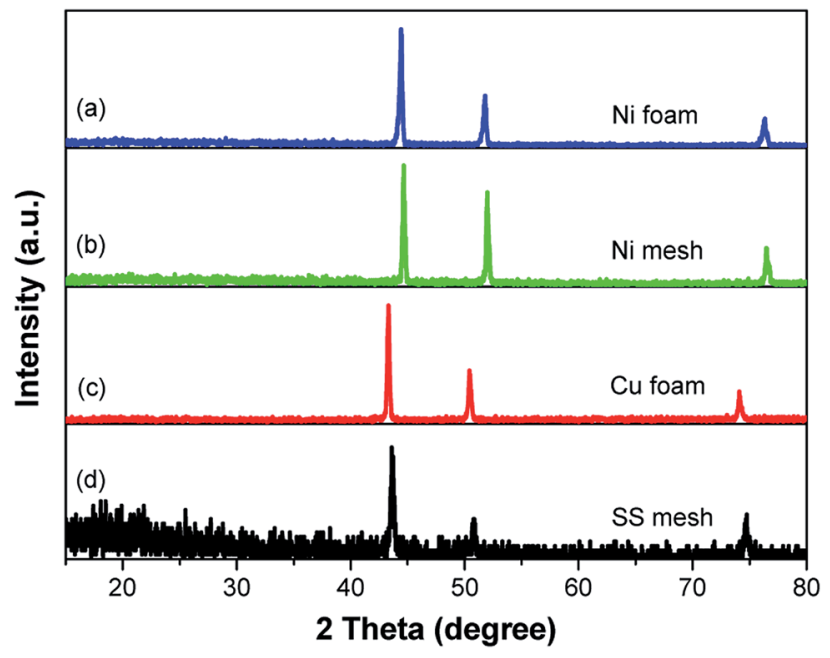

Fig. 1 The XRD patterns of $\mathrm{Ni}$ foam, Ni mesh, Cu foam and SS mesh before use.

The morphologies of these conductive substrate samples were measured by scanning electron microscopy (SEM). The low magnification SEM images show that the Ni foam and SS mesh have 3D skeleton morphology and 2D structure, respectively (Fig. 2A and C). Both of which possess rough surfaces (Fig. 2B and $\mathrm{D}$ ). The morphologies of $\mathrm{Cu}$ foam and $\mathrm{Ni}$ mesh are similar to that of Ni foam and SS mesh, respectively (Fig. S1 $\dagger$ ).
The chemical binding state and elemental composition of the Ni foam and SS mesh were investigated by XPS. The survey XPS spectrum of $\mathrm{Ni}$ foam contains $\mathrm{Ni}, \mathrm{C}$ and $\mathrm{O}$ elements (Fig. S2A $\dagger$ ), and the SS mesh mainly contains $\mathrm{Fe}, \mathrm{Cr}$, $\mathrm{C}$ and $\mathrm{O}$ elements (Fig. S2B $\dagger$ ). Fig. 3A shows the high resolution Ni 2p XPS of Ni foam. The peaks at binding energies of 873.6 and $855.6 \mathrm{eV}$ can be assigned to $\mathrm{Ni} 2 \mathrm{p}_{1 / 2}$ and $\mathrm{Ni} 2 \mathrm{p}_{3 / 2}$ of $\mathrm{NiO}$, respectively. ${ }^{44}$ The satellite peak at around $879.5 \mathrm{eV}$ and $861.2 \mathrm{eV}$ are two shake-up type peaks of nickel at the high binding energy side of the Ni $2 \mathrm{p}_{1 / 2}$ and $\mathrm{Ni} 2 \mathrm{p}_{3 / 2}$ edge. ${ }^{45}$ The small peak at about $852.1 \mathrm{eV}$ is ascribed to $\mathrm{Ni} 2 \mathrm{p}_{3 / 2}$ of the metallic Ni. ${ }^{46}$ It is worth pointing out that the XPS peak for metallic $\mathrm{Ni}$ is much weaker than that of $\mathrm{NiO}$, similar phenomenon was also observed in previous publications. ${ }^{47}$ This indicated that the surface of $\mathrm{Ni}$ foam was oxidized before XPS measurement. Fig. 3B shows the high resolution Fe 2p XPS spectrum of SS mesh. It can be seen that there are five peaks at binding energies of 706.4, 709.9, 712.1, 722.9 and $724.8 \mathrm{eV}$, which can be assigned to $\mathrm{Fe} 2 \mathrm{p}_{3 / 2}$ and $\mathrm{Fe} 2 \mathrm{p}_{1 / 2}$, respectively. The position of these primary peaks is consistent with that of the core-level XPS spectrum of metallic Fe, $\mathrm{FeO}$ and $\mathrm{Fe}_{2} \mathrm{O}_{3}$. The peaks at 706.4 is $\mathrm{Fe}^{0} 2 \mathrm{p}_{3 / 2}$, the peaks at 709.9 and $722.9 \mathrm{eV}$ are assigned to the $\mathrm{Fe} 2 \mathrm{p}_{3 / 2}$ and $\mathrm{Fe} 2 \mathrm{p}_{1 / 2}$ of FeO. ${ }^{48}$ While the peaks at 712.1 and $724.8 \mathrm{eV}$ are assigned to the Fe $2 \mathrm{p}_{3 / 2}$ and $\mathrm{Fe} 2 \mathrm{p}_{1 / 2}$ of $\mathrm{Fe}_{2} \mathrm{O}_{3} \cdot{ }^{48,49}$ The other elements, such as $\mathrm{Cr}$, Si and Mn were not displayed obviously in the survey spectrum, but clearly observed in the high resolution XPS spectra (Fig. S2†).
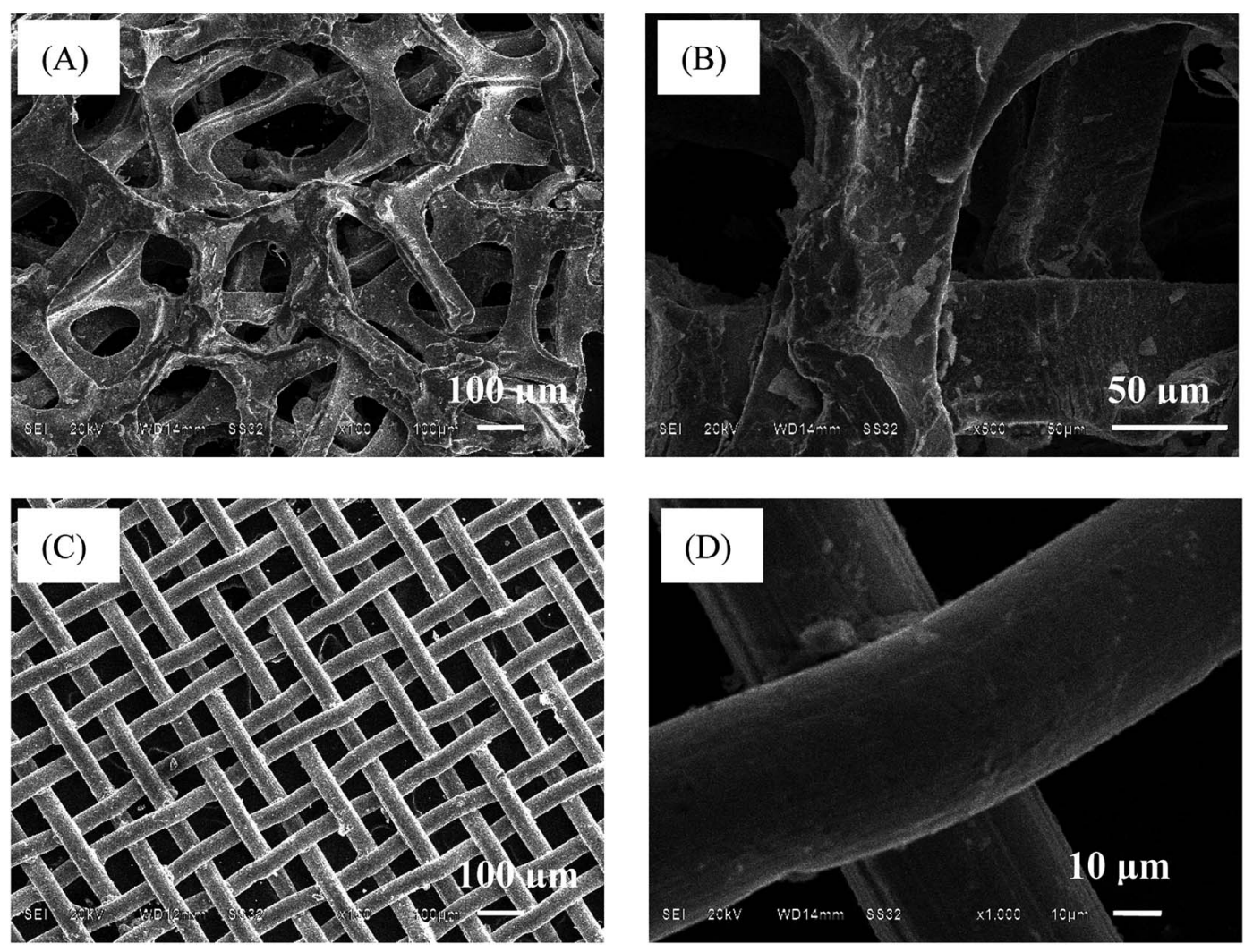

Fig. 2 The SEM images of Ni foam ( $A$ and $B$ ) and SS mesh ( $C$ and $D$ ) before use at low and high magnification. 

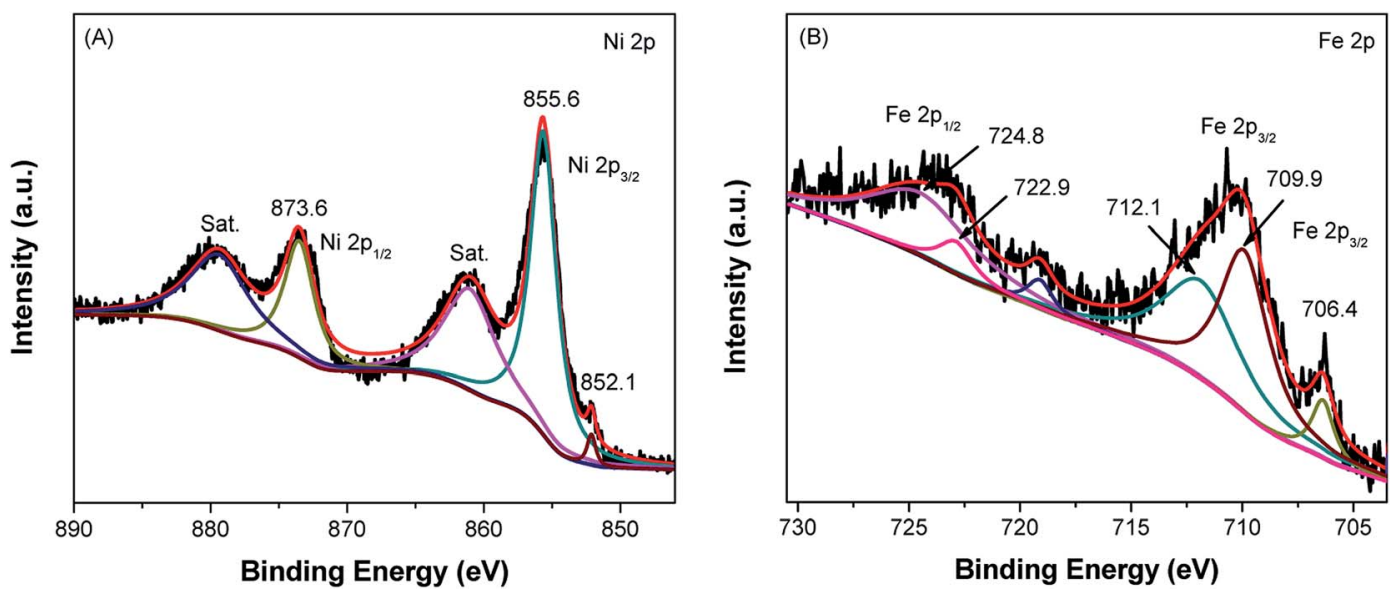

Fig. 3 The high resolution XPS spectra of (A) Ni 2p of Ni foam; (B) Fe 2p of SS mesh before use.

\subsection{HER performances}

The electrocatalytic activity of these conductive substrates for HER was evaluated by linear sweep voltammetry (LSV) in a standard three-electrode system. The HER polarization curves were recorded by LSV at the slow scan rate of $2 \mathrm{mV} \mathrm{s}^{-1}$ to minimize the diffusion limitations and capacitive current interference. For comparison, the electrocatalytic performances of commercial Pt/C, commonly used GCE and ITO were also measured under the same conditions. Fig. 4A shows the polarization curves of all these materials. The commercial $\mathrm{Pt} / \mathrm{C}$ catalyst has the best HER activity and provided a near zero onset potential, while the current density of GCE and ITO do not show obvious increase in the potential range of 0 to $-500 \mathrm{mV}$, indicating their low electrocatalytic activity towards HER. The Ni foam exhibits an onset potential of about $-120 \mathrm{mV}$, and achieves the overpotential of $217 \mathrm{mV}$ at the current density of $10 \mathrm{~mA}$ $\mathrm{cm}^{-2}, 292 \mathrm{mV}$ at $30 \mathrm{~mA} \mathrm{~cm}{ }^{-2}$ and $341 \mathrm{mV}$ at $50 \mathrm{~mA} \mathrm{~cm}$. Although the Ni mesh gave a similar onset potential to Ni foam, it needed a higher overpotential of $275 \mathrm{mV}$ to obtain a current density of $10 \mathrm{~mA} \mathrm{~cm}{ }^{-2}$. Whereas, the $\mathrm{Cu}$ foam and SS mesh required an even higher overpotential of 372 and $420 \mathrm{mV}$, respectively, to achieve the current density of $10 \mathrm{~mA} \mathrm{~cm}^{-2}$. Even though the electrocatalytic performance of Ni foam is not as good as that of $\mathrm{Pt} / \mathrm{C}$ catalyst, it was substantially comparable to or even better than some reported electrocatalysts that prepared in laboratory by researchers (Table S1 $\dagger$ ). Tafel slope was determined by fitting the linear regions of Tafel plots to the Tafel equation. The Tafel slope of $\mathrm{Ni}$ foam was $130 \mathrm{mV} \mathrm{dec}^{-1}$, smaller than that of Ni mesh, Cu foam and SS mesh, suggesting its fast kinetic process.

EIS was measured to gain further insight in the kinetics at the interface of the catalyst and electrolyte. $R_{\mathrm{ct}}$ is well-correlated to electrocatalytic kinetics, arising from the charge transfer resistance at the interface between the catalyst and the electrolyte. It is generally accepted that small $R_{\mathrm{ct}}$ values give rise to rapid charge transfer kinetics. ${ }^{26}$ Fig. $4 \mathrm{C}$ shows the Nyquist plots of Ni foam, Ni mesh, $\mathrm{Cu}$ foam and SS mesh. The $R_{\mathrm{ct}}$ of $\mathrm{Ni}$ foam was estimated to be about $25 \Omega$ from the diameter of semicircle, which was smaller than that of Ni mesh, Cu foam and SS mesh. The small $R_{\text {ct }}$ of Ni foam suggested the fast kinetics in HER, which is in accordance with the Tafel slope and LSV results.

Since the long-term cycling stability is also an important factor in assessing an electrocatalyst, the stability of Ni foam was first evaluated by chronopotentiometry (CP) in $1 \mathrm{M} \mathrm{KOH}$ solution at constant current density of $-10,-30$ and $-50 \mathrm{~mA}$ $\mathrm{cm}^{-2}$ for $20 \mathrm{~h}$, respectively. As shown in Fig. 4D, the potential increase is negligible, indicating that $\mathrm{Ni}$ foam has excellent stability in alkaline conditions. To further confirm the excellent stability of $\mathrm{Ni}$ foam, continuous $\mathrm{CV}$ measurement was performed in the range of -0.3 to $0 \mathrm{~V}$ at $100 \mathrm{mV} \mathrm{s}^{-1}$ for 2000 cycles. As can be seen in Fig. 4E, the LSV curve of Ni foam after 2000 cycles of CV measurement was still similar to the first cycle. These results undoubtedly indicated that the $\mathrm{Ni}$ foam has excellent catalytic activity and stability for HER. In addition, after the stability test, the XRD pattern (Fig. S4 $\dagger$ ), SEM images (Fig. S1E and $\mathrm{F}^{\dagger}$ ) and XPS spectrum (Fig. S5 $\dagger$ ) of Ni foam was conducted, a comparative XRD and SEM study of $\mathrm{Ni}$ foam indicates no obvious change before and after the HER process. The XPS data after the stability test showed that the metallic nickel on the surface of the $\mathrm{Ni}$ foam was oxidized to $\mathrm{NiO}$, indicating that $\mathrm{NiO}$ is the active substance of hydrogen evolution reaction.

\subsection{OER performances}

To study the bifunctional catalytic activity of all substrates, we also tested their OER activity by LSV with a standard threeelectrode system. Fig. 5A shows the LSV curves for OER at a scan rate of $2 \mathrm{mV} \mathrm{s}^{-1}$ in $1 \mathrm{M} \mathrm{KOH}$ solution. The polarization curve of $\mathrm{Ni}$ foam has a distinct oxidative peak at $1.37 \mathrm{~V}$ versus RHE, which is attributed to the oxidation of Ni species. ${ }^{50}$ Different from the activity order of HER, the Ni foam presents the relatively poor OER activity, it achieved the overpotential of $337 \mathrm{mV}$ at the current density of $10 \mathrm{~mA} \mathrm{~cm}^{-2}$. At the same time, the current density of GCE and ITO did not show obvious increase in the potential range of 1.23 to $1.8 \mathrm{~V}$, the $\mathrm{Cu}$ foam and Ni mesh required a even higher overpotential of 464 and 

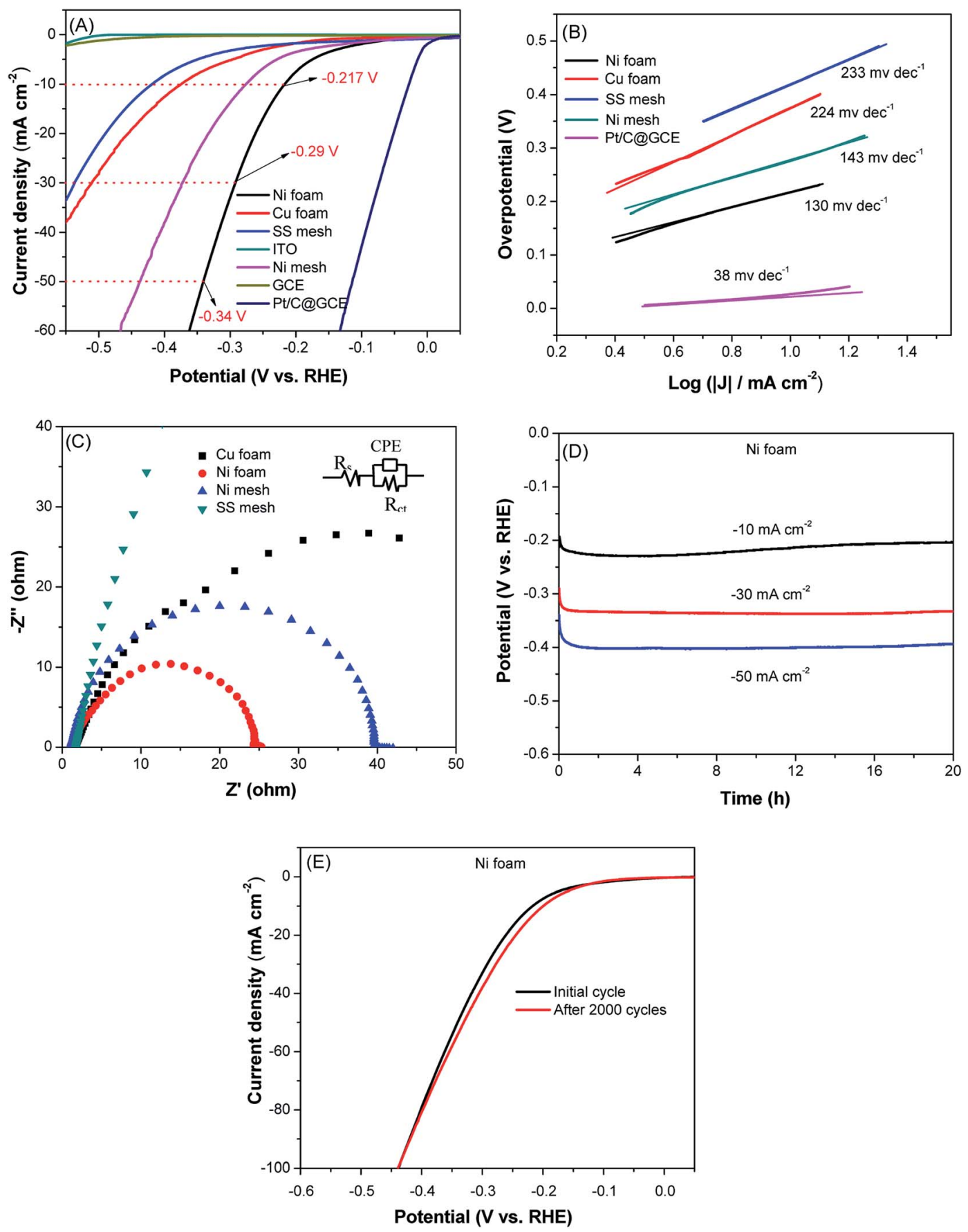

Fig. 4 (A) LSV curves measured at $2 \mathrm{mV} \mathrm{s}^{-1}$ in $1 \mathrm{M} \mathrm{KOH}$ solution for HER and (B) the corresponding Tafel slopes; (C) Nyquist plots of EIS of samples from $10^{5} \mathrm{~Hz}$ to $0.1 \mathrm{~Hz}$ with an amplitude of $5 \mathrm{mV}$; (D) chronopotentiometric curves at different current density; (E) LSV curves obtained with $\mathrm{Ni}$ foam before and after 2000 cycles of an accelerated stability test.

$491 \mathrm{mV}$, respectively, to achieve the current density of $10 \mathrm{~mA}$ $\mathrm{cm}^{-2}$, indicating their low electrocatalytic activity towards OER. Contrary to HER, the SS mesh exhibits the highest OER activity among these substrates studied. It achieved the current density of 10,30 and $50 \mathrm{~mA} \mathrm{~cm} \mathrm{~cm}^{-2}$ at potential of $1.507,1.556$ and $1.597 \mathrm{~V}$, respectively. Note that the OER activity of SS mesh is even better than that of $\mathrm{RuO}_{2} \cdot \mathrm{RuO}_{2}$ achieved the overpotential of $303 \mathrm{mV}$ at the current density of $10 \mathrm{~mA} \mathrm{~cm}{ }^{-2}$, while the SS mesh producing a current density of $10 \mathrm{~mA} \mathrm{~cm}^{-2}$ at an overpotential of $277 \mathrm{mV}$. The overpotential values compare favorably with the behavior of most previously reported materials for OER (Table S2 $\dagger$ ). Since the electrocatalytic reaction current is directly proportional to the oxygen yield, the higher current density here indicates prominent oxygen evolution behavior of SS mesh, highlighting its excellent performance for OER. Fig. 5B shows the Tafel plots of various substrates. The Tafel slope of SS 

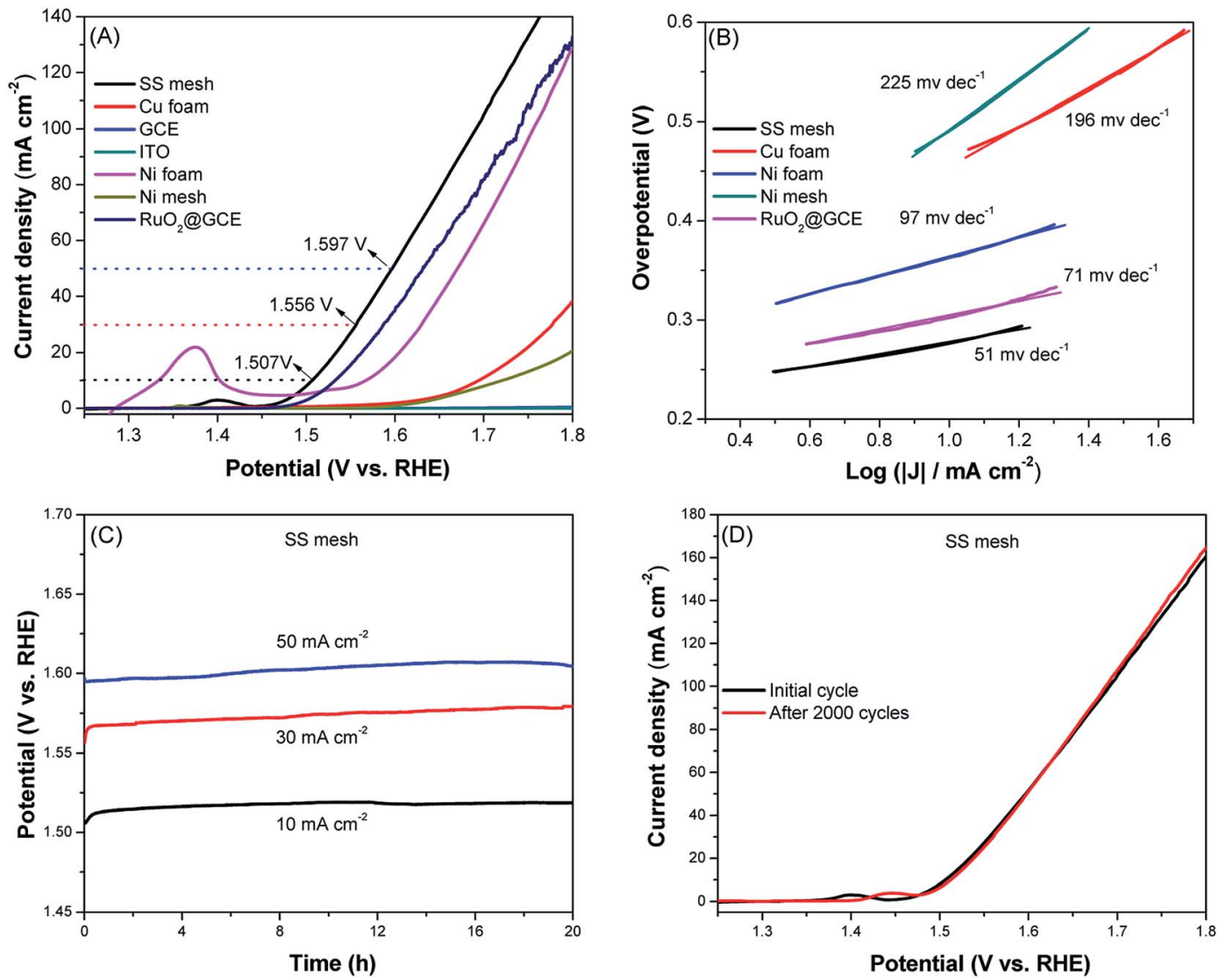

Fig. 5 (A) The LSV curves measured at $2 \mathrm{mV} \mathrm{s}^{-1}$ in $1 \mathrm{M} \mathrm{KOH}$ solution for OER and (B) the corresponding Tafel slopes; (C) chronopotentiometric curves at different current density; (D) LSV curves obtained with SS mesh before and after 2000 cycles of an accelerated stability test.

mesh is $51 \mathrm{mV} \mathrm{dec}^{-1}$, which is the smallest among these catalysts, implying its best catalytic performance in OER.

The long-term stability of the electrocatalyst is another important criterion for practical applications. In order to detect the durability of the SS mesh in an alkaline environment, we tested the cycling stability of SS mesh in $1 \mathrm{M} \mathrm{KOH}$ solution. The stability test was performed by chronopotentiometry at a series of constant current density of 10,30 and $50 \mathrm{~mA} \mathrm{~cm}^{-2}$. As shown in Fig. 5C, the operating potentials of SS mesh are nearly constant, the potential increase of was only about $10 \mathrm{mV}$ with $20 \mathrm{~h}$ chronopotentiometry test, indicating the excellent stability of SS mesh. Then, the stability was further estimated by the continuous CV measurements, which were performed at a scan rate of $100 \mathrm{mV} \mathrm{s}^{-1}$ in the range from 1.4 to $1.6 \mathrm{~V}$ for 2000 cycles, its attenuation is negligible, verifying its excellent stability. The XRD patterns (Fig. S4 $\dagger$ ) and SEM images (Fig. S1G and $\mathrm{H} \dagger$ ) after the stability test were consistent with the original crystal phases and morphologies. The XPS (Fig. S6†) measurement after the OER stability test showed that the surface of the SS mesh changed to some degree after OER performance. Both Fe and Ni elements were existed as $\mathrm{FeO}_{x}$ and NiO (Fig. S6 and ESI for details $\dagger$ ). According to the experimental results and the earlier studies, ${ }^{51,52}$ the $\mathrm{FeO}, \mathrm{Fe}_{2} \mathrm{O}_{3}$ and $\mathrm{NiO}$ on the surface of SS mesh was proposed to be the active species for oxygen evolution reaction.
Moreover, EIS investigations were conducted to further explore the OER kinetics in catalysis. As shown in Fig. S3B,$\dagger$ the SS mesh has relatively lower charge transfer resistance for OER, indicating its faster electron transfer rate during the OER process. This further suggests that SS mesh is more advantageous for OER.

On the basis of the excellent HER performance of $\mathrm{Ni}$ foam and the OER performance of SS mesh in alkaline solution, we further studied their catalytic performance for overall water splitting in a two-electrode system by using $\mathrm{Ni}$ foam as cathode and SS mesh as anode. As shown in Fig. 6A, the obvious hydrogen and oxygen bubbles are formed on $\mathrm{Ni}$ foam and SS mesh, respectively, in $1 \mathrm{M} \mathrm{KOH}$ solution. Fig. 6B shows the LSV polarization curve of SS mesh $(+) \|$ Ni foam $(-)$. A current density of $10 \mathrm{~mA} \mathrm{~cm} \mathrm{~cm}^{-2}$ can be achieved with a cell potential of $1.74 \mathrm{~V}$, which is comparable to or even better than many other reported bifunctional water-splitting catalysts (Table S3†). Furthermore, as shown in Fig. 6C, the potential difference $(\Delta V)$ at 10,30 and $50 \mathrm{~mA} \mathrm{~cm}^{-2}$ between HER and OER was $1.73,1.85$ and $1.94 \mathrm{~V}$, respectively, which are very close to the actual measured values of 1.74, 1.86 and $1.93 \mathrm{~V}$ (Fig. 6B), indicating the steady-state performance of the HER, OER and overall water splitting process. 

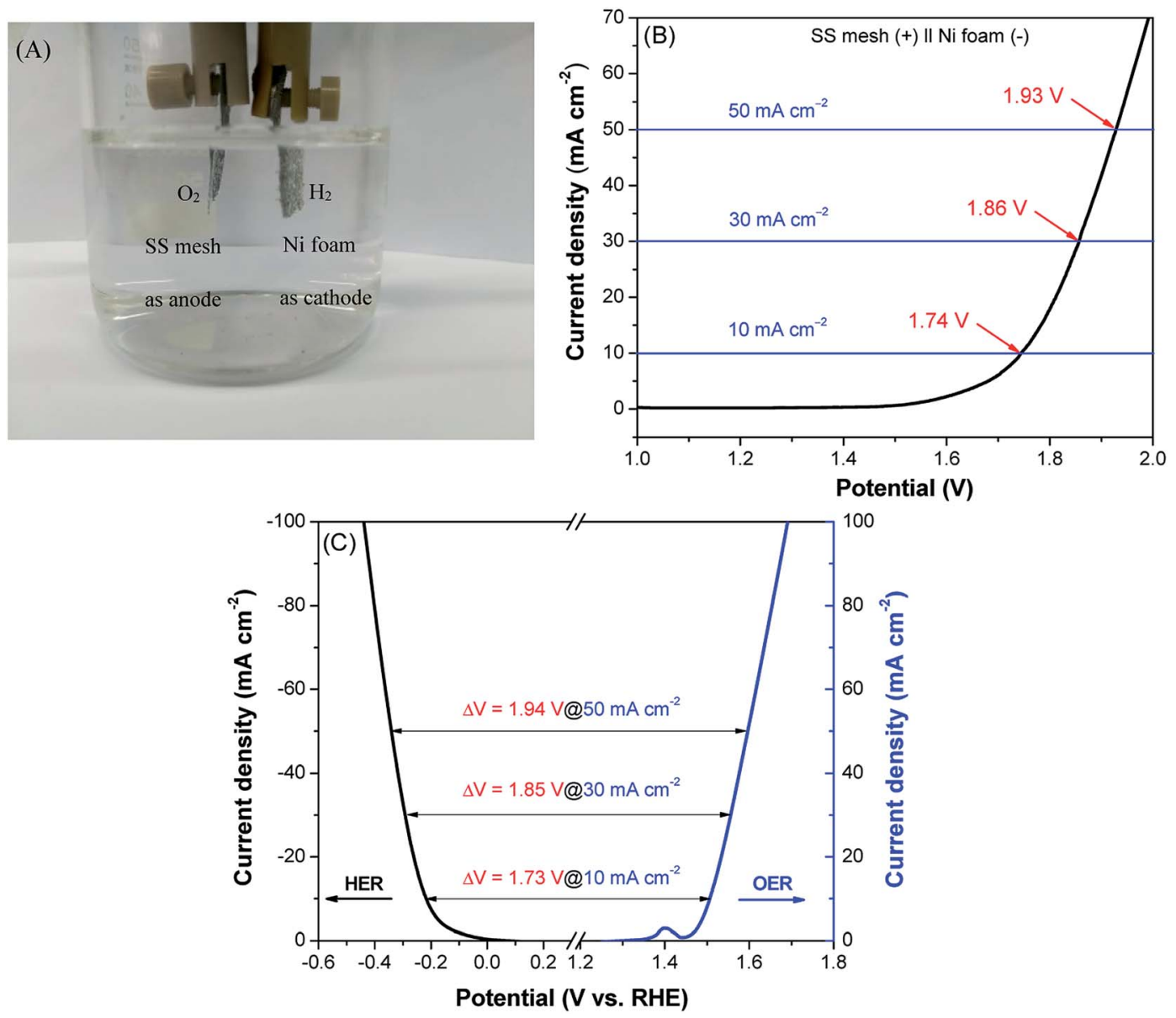

Fig. 6 (A) Optical photograph of the generation of hydrogen and oxygen bubbles on Ni foam and SS mesh; (B) polarization curve in a twoelectrode system with SS mesh (+)\|Ni foam (-); (C) polarization curves of SS mesh for OER and Ni foam for HER.

\section{Conclusions}

In summary, we investigated several commonly used conductive substrates as electrocatalysts for HER and OER under alkaline conditions. The electrochemical measurements revealed that $\mathrm{Ni}$ foam shows the best catalytic activity for HER and SS mesh shows the best catalytic activity for OER. The OER activity of SS mesh is even better than that of commercial $\mathrm{RuO}_{2}$ catalyst. Both $\mathrm{Ni}$ foam and SS mesh showed excellent stability as tested by chronopotentiometry. Furthermore, the assembled SS mesh $(+)|| \mathrm{Ni}$ foam $(-)$ system for water splitting afforded a current density of $10 \mathrm{~mA}$ $\mathrm{cm}^{-2}$ at a small cell voltage of $1.74 \mathrm{~V}$. This work provides a feasible way for the production of hydrogen economically by electrochemical water splitting with inexpensive and commercial available Ni foam and SS mesh as cathode and anode electrocatalysts.

\section{Conflicts of interest}

There are no conflicts of interest to declare.

\section{Acknowledgements}

This work was supported by the Meritocracy Research Funds of China West Normal University (17YC034), and the Open Project of Chemical Synthesis and Pollution Control Key Laboratory of Sichuan Province (CSPC2016-3-2).

\section{Notes and references}

1 N. S. Lewis and D. G. Nocera, Powering the planet: chemical challenges in solar energy utilization, Proc. Natl. Acad. Sci. U. S. A., 2006, 103, 15729-15735.

2 M. I. Jamesh, Recent progress on earth abundant hydrogen evolution reaction and oxygen evolution reaction bifunctional electrocatalyst for overall water splitting in alkaline media, J. Power Sources, 2016, 333, 213-236.

3 Z. Han, X. Liang, S. Wang, L. Zhou and Z. Zhao, One-step synthesis of $\mathrm{Ni}-\mathrm{Mo}-\mathrm{S} / \mathrm{MoO}_{x}$ composite self-supported on $\mathrm{Ni}$ foam for efficient electrocatalytic hydrogen evolution, Mater. Lett., 2019, 246, 63-66.

4 M. Yao, B. Sun, N. Wang, W. Hu and S. Komarneni, Selfgenerated $\mathrm{N}$-doped anodized stainless steel mesh for an efficient and stable overall water splitting electrocatalyst, Appl. Surf. Sci., 2019, 480, 655-664.

5 S. Wang, L. Xu and W. Lu, Synergistic effect: hierarchical $\mathrm{Ni}_{3} \mathrm{~S}_{2} @ \mathrm{Co}(\mathrm{OH})_{2}$ heterostructure as efficient bifunctional electrocatalyst for overall water splitting, Appl. Surf. Sci., 2018, 457, 156-163. 
6 Y. Jiao, Y. Zheng, M. Jaroniec and S. Z. Qiao, Design of electrocatalysts for oxygen- and hydrogen-involving energy conversion reactions, Chem. Soc. Rev., 2015, 44, 2060-2086.

7 M. Kuang and G. Zheng, Nanostructured bifunctional redox electrocatalysts, Small, 2016, 12, 5656-5675.

8 C. C. McCrory, S. Jung, I. M. Ferrer, S. M. Chatman, J. C. Peters and T. F. Jaramillo, Benchmarking hydrogen evolving reaction and oxygen evolving reaction electrocatalysts for solar water splitting devices, J. Am. Chem. Soc., 2015, 137, 4347-4357.

9 Y. Zhu, W. Zhou, Z. G. Chen, Y. Chen, C. Su, M. O. Tadé and Z. Shao, $\operatorname{SrNb}_{(0.1)} \mathrm{Co}_{(0.7)} \mathrm{Fe}_{(0.2)} \mathrm{O}_{(3-\delta)}$ perovskite as a nextgeneration electrocatalyst for oxygen evolution in alkaline solution, Angew. Chem., Int. Ed., 2015, 54, 3897-3901.

10 Y. Sun, S. Gao, F. Lei, J. Liu, L. Liang and Y. Xie, Atomicallythin non-layered cobalt oxide porous sheets for highly efficient oxygen-evolving electrocatalysts, Chem. Sci., 2014, 5, 3976-3982.

11 H. Chen, Q. Zhao, L. Gao, J. Ran and Y. Hou, Water-plasma assisted synthesis of oxygen-enriched $\mathrm{Ni}-\mathrm{Fe}$ layered double hydroxide nanosheets for efficient oxygen evolution reaction, ACS Sustainable Chem. Eng., 2019, 7, 4247-4254.

12 J. Huang, J. Han, R. Wang, Y. Zhang, X. Wang, X. Zhang, Z. Zhang, Y. Zhang, B. Song and S. Jin, Improving electrocatalysts for oxygen evolution using $\mathrm{Ni}_{x} \mathrm{Fe}_{3-x} \mathrm{O}_{4} / \mathrm{Ni}$ hybrid nanostructures formed by solvothermal synthesis, ACS Energy Lett., 2018, 3, 1698-1707.

13 Y. Zhang, X. Wang, F. Luo, Y. Tan, L. Zeng, B. Fang and A. Liu, Rock salt type $\mathrm{NiCo}_{2} \mathrm{O}_{3}$ supported on ordered mesoporous carbon as a highly efficient electrocatalyst for oxygen evolution reaction, Appl. Catal., B, 2019, 256, 117852.

14 W. Zhong, Z. Lin, S. Feng, D. Wang, S. Shen, Q. Zhang, L. Gu, Z. Wang and B. Fang, Improved oxygen evolution activity of $\mathrm{IrO}_{2}$ by in situ engineering of an ultra-small Ir sphere shell utilizing a pulsed laser, Nanoscale, 2019, 11, 4407-4413.

$15 \mathrm{~F}$. Song and $\mathrm{X}$. $\mathrm{Hu}$, Ultrathin cobalt-manganese layered double hydroxide is an efficient oxygen evolution catalyst, J. Am. Chem. Soc., 2014, 136, 16481-16484.

16 X. Long, J. Li, S. Xiao, K. Yan, Z. Wang, H. Chen and S. Yang, A strongly coupled graphene and FeNi double hydroxide hybrid as an excellent electrocatalyst for the oxygen evolution reaction, Angew. Chem., Int. Ed. Engl., 2014, 53, 7584-7588.

17 J. Jiang, A. Zhang, L. Li and L. Ai, Nickel-cobalt layered double hydroxide nanosheets as high-performance electrocatalyst for oxygen evolution reaction, J. Power Sources, 2015, 278, 445-451.

18 Q. Zhou, Y. Chen, G. Zhao, Y. Lin, Z. Yu, X. Xu, X. Wang, H. K. Liu, W. Sun and S. X. Dou, Active-site-enriched irondoped nickel/cobalt hydroxide nanosheets for enhanced oxygen evolution reaction, ACS Catal., 2018, 8, 5382-5390.

19 J. Xie, J. Zhang, S. Li, F. Grote, X. Zhang, H. Zhang, R. Wang, Y. Lei, B. Pan and Y. Xie, Controllable disorder engineering in oxygen-incorporated $\mathrm{MoS}_{2}$ ultrathin nanosheets for efficient hydrogen evolution, J. Am. Chem. Soc., 2014, 136, 17881-17888.
20 Y. F. Xu, M. R. Gao, Y. R. Zheng, J. Jiang and S. H. Yu, Nickel/ nickel(II) oxide nanoparticles anchored onto cobalt(Iv) diselenide nanobelts for the electrochemical production of hydrogen, Angew. Chem., 2013, 125, 8708-8712.

21 D. Kong, H. Wang, Z. Lu and Y. Cui, $\mathrm{CoSe}_{2}$ nanoparticles grown on carbon fiber paper: an efficient and stable electrocatalyst for hydrogen evolution reaction, J. Am. Chem. Soc., 2014, 136, 4897-4900.

22 Y. Du, S. Khan, X. Zhang, G. Yu, R. Liu, B. Zheng, R. Nadimicherla, D. Wu and R. Fu, In situ preparation of porous carbon nanosheets loaded with metal chalcogenides for a superior oxygen evolution reaction, Carbon, 2019, 149, 144-151.

23 E. J. Popczun, C. G. Read, C. W. Roske, N. S. Lewis and R. E. Schaak, Highly active electrocatalysis of the hydrogen evolution reaction by cobalt phosphide nanoparticles, Angew. Chem., Int. Ed., 2014, 53, 5427-5430.

24 E. J. Popczun, J. R. Mckone, C. G. Read, A. J. Biacchi, A. M. Wiltrout, N. S. Lewis and R. E. Schaak, Nanostructured nickel phosphide as an electrocatalyst for the hydrogen evolution reaction, J. Am. Chem. Soc., 2013, 135, 9267-9270.

25 M. Ledendecker, C. S. Krick, C. Papp, H. P. Steinrück, M. Antonietti and M. Shalom, The synthesis of nanostructured $\mathrm{Ni}_{5} \mathrm{P}_{4}$ films and their use as a non-noble bifunctional electrocatalyst for full water splitting, Angew. Chem., 2015, 54, 12361-12365.

26 C. Du, M. Shang, J. Mao and W. Song, Hierarchical MoP/Ni $/{ }_{2} \mathrm{P}$ heterostructures on nickel foam for efficient water splitting, J. Mater. Chem. A, 2017, 5, 15940-15949.

27 Q. Fu, T. Wu, G. Fu, T. Gao, J. Han, T. Yao, Y. Zhang, W. Zhong, X. Wang and B. Song, Skutterudite-type ternary $\mathrm{Co}_{1-x} \mathrm{Ni}_{x} \mathrm{P}_{3}$ nanoneedle array electrocatalysts for enhanced hydrogen and oxygen evolution, ACS Energy Lett., 2018, 3, 1744-1752.

28 D. Liu, Q. Lu, Y. Luo, X. Sun and A. M. Asiri, $\mathrm{NiCo}_{2} \mathrm{~S}_{4}$ nanowires array as an efficient bifunctional electrocatalyst for full water splitting with superior activity, Nanoscale, 2015, 7, 15122-15126.

29 A. Sivanantham, P. Ganesan and S. Shanmugam, Hierarchical $\mathrm{NiCo}_{2} \mathrm{~S}_{4}$ nanowire arrays supported on $\mathrm{Ni}$ foam: an efficient and durable bifunctional electrocatalyst for oxygen and hydrogen evolution reactions, Adv. Funct. Mater., 2016, 26, 4661-4672.

30 L. L. Feng, G. Yu, Y. Wu, G. D. Li, H. Li, Y. Sun, T. Asefa, W. Chen and $\mathrm{X}$. Zou, High-index faceted $\mathrm{Ni}_{3} \mathrm{~S}_{2}$ nanosheet arrays as highly active and ultrastable electrocatalysts for water splitting, J. Am. Chem. Soc., 2015, 137, 14023-14026.

31 W. Zhao, S. Wang, C. Feng, H. Wu, L. Zhang and J. Zhang, Novel cobalt-doped $\mathrm{Ni}_{0.85} \mathrm{Se}$ chalcogenides $\left(\mathrm{Co}_{x} \mathrm{Ni}_{0.85-x} \mathrm{Se}\right)$ as high active and stable electrocatalysts for hydrogen evolution reaction in electrolysis water splitting, ACS Appl. Mater. Interfaces, 2018, 10, 40491-40499.

32 R. Wang, X. Li, T. Gao, T. Yao, S. Liu, X. Wang, J. Han, P. Zhang, X. Cao, X. Zhang, Y. Zhang and B. Song, Beyond 1T-phase? Synergistic electronic structure and defects engineering in $2 \mathrm{H}-\mathrm{MoS}_{2 x} \mathrm{Se}_{2(1-x)}$ nanosheets for enhanced 
hydrogen evolution reaction and sodium storage, ChemCatChem, 2019, 11, 3200-3211.

33 M. H. Suliman, A. Adam, M. N. Siddiqui, Z. H. Yamani and M. Qamar, Facile synthesis of ultrathin interconnected carbon nanosheets as a robust support for small and uniformly-dispersed iron phosphide for the hydrogen evolution reaction, Carbon, 2019, 144, 764-771.

$34 \mathrm{~J}$. Wang and F. Ciucci, In situ synthesis of bimetallic phosphide with carbon tubes as an active electrocatalyst for oxygen evolution reaction, Appl. Catal., B, 2019, 254, 292-299.

35 R. Li, D. Zhou, J. Luo, W. Xu, J. Li, S. Li, P. Cheng and D. Yuan, The urchin-like sphere arrays $\mathrm{Co}_{3} \mathrm{O}_{4}$ as a bifunctional catalyst for hydrogen evolution reaction and oxygen evolution reaction, J. Power Sources, 2017, 341, 250256.

36 E. Telli and D. Özer, Fe-Cu coated nickel mesh usage as cathode catalyst for hydrogen evolution reaction, Int. J. Hydrogen Energy, 2018, 43, 7366-7371.

37 J. Jiang, Q. Liu, C. Zeng and L. Ai, Cobalt/molybdenum carbide@N-doped carbon as bifunctional electrocatalysts for hydrogen and oxygen evolution reactions, J. Mater. Chem. A, 2017, 5, 16929-16935.

38 J. S. Chen, J. Ren, M. Shalom, T. Fellinger and M. Antonietti, Stainless steel mesh-supported NiS nanosheet array as highly efficient catalyst for oxygen evolution reaction, ACS Appl. Mater. Interfaces, 2016, 8, 5509-5516.

$39 \mathrm{X}$. Fan, H. Zhou and X. Guo, WC nanocrystals grown on vertically aligned carbon nanotubes: an efficient and stable electrocatalyst for hydrogen evolution reaction, ACS Nano, 2015, 9, 5125-5134.

40 Y. J. Leem, K. Cho, K. H. Oh, S. H. Han, K. M. Nam and J. Chang, A self-assembled Ni(cyclam)-BTC network on ITO for an oxygen evolution catalyst in alkaline solution, Chem. Commun., 2017, 53, 3454-3457.

41 X. Yang, A. Y. Lu, Y. Zhu, M. N. Hedhili, S. Min, K. W. Huang, Y. Han and L. J. Li, CoP nanosheet assembly grown on carbon cloth: a highly efficient electrocatalyst for hydrogen generation, Nano Energy, 2015, 15, 634-641.

42 F. Yu, F. Li and L. Sun, Stainless steel as an efficient electrocatalyst for water oxidation in alkaline solution, Int. J. Hydrogen Energy, 2016, 41, 5230-5233.
43 U. Y. Qazi, C. Z. Yuan, N. Ullah, Y. F. Jiang, M. Imran, A. Zeb, S. J. Zhao, R. Javaid and A. W. Xu, One-step growth of ironnickel bimetallic nanoparticles on FeNi alloy foils: highly efficient advanced electrodes for the oxygen evolution reaction, ACS Appl. Mater. Interfaces, 2017, 9, 28627-28634.

44 J. Landon, E. Demeter, N. İnoğlu, C. Keturakis, I. E. Wachs, R. Vasić, A. I. Frenkel and J. R. Kitchin, Spectroscopic characterization of mixed $\mathrm{Fe}-\mathrm{Ni}$ oxide electrocatalysts for the oxygen evolution reaction in alkaline electrolytes, $A C S$ Catal., 2012, 2, 1793-1801.

45 C. Jin, F. Lu, X. Cao, Z. Yang and R. Yang, Facile synthesis and excellent electrochemical properties of $\mathrm{NiCo}_{2} \mathrm{O}_{4}$ spinel nanowire arrays as a bifunctional catalyst for the oxygen reduction and evolution reaction, J. Mater. Chem. A, 2013, 1, 12170-12177.

46 G. Abellán, H. Prima-García and E. Coronado, Graphene enhances the magnetoresistance of $\mathrm{FeNi}_{3}$ nanoparticles in hierarchical $\mathrm{FeNi}_{3}$-graphene nanocomposites, J. Mater. Chem. C, 2016, 4, 2252-2258.

47 J. Zhao, X. Ren, Q. Han, D. Fan, X. Sun, X. Kuang, Q. Wei and D. Wu, Ultra-thin wrinkled $\mathrm{NiOOH}-\mathrm{NiCr}_{2} \mathrm{O}_{4}$ nanosheets on $\mathrm{Ni}$ foam: an advanced catalytic electrode for oxygen evolution reaction, Chem. Commun., 2018, 54, 4987-4990.

$48 \mathrm{H}$. Gu, Y. Jiang and M. Yan, Defect-induced room temperature ferromagnetism in Fe and $\mathrm{Na}$ co-doped $\mathrm{ZnO}$ nanoparticles, J. Alloys Compd., 2012, 521, 90-94.

49 H. Xing, Z. Liu, L. Lin, L. Wang, D. Tan, Y. Gan, X. Ji and $\mathrm{G}$. $\mathrm{Xu}$, Excellent microwave absorption properties of $\mathrm{Fe}$ ion-doped $\mathrm{SnO}_{2} /$ multi-walled carbon nanotube composites, RSC Adv., 2016, 6, 41656-41664.

50 L. A. Stern, L. Feng, F. Song and $\mathrm{X}$. $\mathrm{Hu}, \mathrm{Ni}_{2} \mathrm{P}$ as a janus catalyst for water splitting: the oxygen evolution activity of $\mathrm{Ni}_{2} \mathrm{P}$ nanoparticles, Energy Environ. Sci., 2015, 8, 2347-2351.

51 L. Trotochaud, S. L. Young, J. K. Ranney and S. W. Boettcher, Nickel-iron oxyhydroxide oxygen-evolution electrocatalysts: the role of intentional and incidental iron incorporation, $J$. Am. Chem. Soc., 2014, 136, 6744-6753.

52 M. W. Louie and A. T. Bell, An investigation of thin-film NiFe oxide catalysts for the electrochemical evolution of oxygen, J. Am. Chem. Soc., 2013, 135, 12329-12337. 